International Journal of Instruction e-ISSN: 1308-1470 • www.e-iji.net

Article submission code: 20191028013900

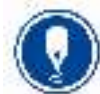

January $2021 \bullet$ Vol.14, No.1

p-ISSN: 1694-609X

pp. 1-16

Received: 28/10/2019

Revision: 29/05/2020
Accepted: 19/06/2020

OnlineFirst:05/10/2020

\title{
The Mediating Effects of Self-Efficacy and Classroom Stress on Professional Development and Student-Centered Instruction
}

\section{Sunghwan Hwang}

Dr., Seoul National University of Education, South Korea, ihwang413@gmail.com

$$
\mid
$$

Professional development (PD) has been widely implemented to shift mathematics instruction practices from teacher-centered (traditional practice) to studentcentered. As such, a study examining mediating factors on the relationship between PD and student-centered instruction is of great importance in enhancing the effectiveness of PD and shifting teacher practice. Although studies examining the mediating effects of contextual factors (e.g., administrative support) on the relationship between PD and instruction abound, studies exploring the effects of teachers' psychological factors on this relationship are relatively scarce. In this study, we examined the mediating effects of mathematics teachers' self-efficacy beliefs and classroom stress on the relationship between PD and student-centered instruction. We used a secondary data set collected for the 2015 Trends in International Mathematics and Science Study (TIMSS). For this data set, 317 teachers of eighth-grade mathematics, selected from 150 schools in Korea, were surveyed, and an analysis was conducted using structural equation modeling. Our findings revealed significant mediating effects of self-efficacy beliefs on the relationship between PD and student-centered instruction. However, the mediating effects of classroom stress were not significant. Moreover, we found significantly positive direct effects of PD and self-efficacy on student-centered instruction.

Keywords: professional development, student-centered instruction, self-efficacy, classroom stress, structural equation modeling

\section{INTRODUCTION}

Numerous studies on mathematics instruction have emphasized student-centered instruction to enhance student conceptual understanding (Carpenter \& Lehrer, 1999; Heyd-Metzuyanim \& Shabtay, 2019; Ko et al., 2015; Lewis, 2014; Ministry of Education, 2015; Munter et al., 2015; National Council of Teachers of Mathematics [NCTM], 2014; United Kingdom Qualifications and Curriculum Authority, 1999). Furthermore, professional development (PD) has been widely implemented to shift mathematics instruction practices from teacher-centered (traditional practice) to studentcentered (Alamri et al., 2018; Desimone, 2009; Garet et al., 2001; Heck et al., 2019; Jacob et al., 2017; Roschelle et al., 2010; Santagata et al., 2010). PD enhances teachers' understanding of student-centered teaching and helps them acquire new knowledge for

Citation: Hwang, S. (2021). The Mediating Effects of Self-Efficacy and Classroom Stress on Professional Development and Student-Centered Instruction. International Journal of Instruction, 14(1), 1-16. https://doi.org/10.29333/iji.2021.1411a 
teaching mathematics, which in turn positively affects their student-centered instruction (Desimone, 2009; Garet et al., 2001; Lewis, 2014).

The effects of PD on mathematics teachers' student-centered instruction vary according to contextual factors. Studies have showed that contextual factors, such as the administrative support and content, structure, and duration of PD, positively or negatively mediate the relationship between PD and instruction (Desimone, 2009; Garet et al., 2001; Heck et al., 2019; Jacob et al., 2017; Santagata et al., 2010). For example, a principal's lack of support discourages teachers from committing to PD, which nullifies the effects of PD on instruction (Jacob et al., 2017). In addition, the less time teachers have to engage in PD, the less opportunity they have to acquire new mathematical knowledge, and the less effect PD has on instruction (Garet et al., 2001). Therefore, research that examines mediating factors on the relationship between PD and studentcentered instruction is of great importance in enhancing the effectiveness of PD and shifting teachers' instruction practice (Desimone, 2009; Heck et al., 2019).

Surprisingly, empirical studies that explore the mediating effects of teachers' psychological factors on the relationship between PD and instruction are relatively scarce (Thoonen et al., 2011). However, there is growing evidence that psychological factors such as self-efficacy beliefs (Althauser, 2015; Bandura, 1997; Donnell \& Gettinger, 2015; Morali, 2019; Smith, 1996; Zee \& Koomen, 2016) and classroom stress (Galton \& MacBeath, 2008; Ismail et al., 2019; Klassen \& Chiu, 2010; Kyriacou, 2001; Ouellette et al., 2018; Sandilos et al., 2018; Skaalvik \& Skaalvik, 2016, 2017; Wilson, 2002; Yoon, 2002) affect teachers' learning and instruction. Donnell and Gettinger (2015) and Thoonen et al. (2011) argued that there is a need for research to move beyond investigating the mediating effects of contextual factors on the relationship between PD and instruction toward researching the mediating effects of teachers' psychological factors on the relationship. In line with this recommendation and the findings of previous studies, the purpose of this study is to examine whether mathematics teachers' self-efficacy beliefs and classroom stress mediate the effects of PD on student-centered instruction.

\section{LITERATURE REVIEW}

\section{Mathematics Teachers' Instructional Practices}

Traditional mathematics education has focused on procedural fluency, direct teacher instruction, and student rote learning. Teachers believed that the purpose of teaching mathematics was to provide authoritative knowledge and that students' participation should be limited to achieving the goal of acquiring that knowledge (Munter et al., 2015). Teachers dominated classroom discourse and asked students to memorize simple procedures, a practice defined as teacher-centered instruction (Heyd-Metzuyanim \& Shabtay, 2019).

In recent decades, however, mathematics educators have called for teachers to be concerned with students' conceptual understanding (Carpenter \& Lehrer, 1999; Munter et al., 2015; NCTM, 2014). In the United States, NCTM (2014) suggested that teachers should help students learn mathematics through discussion, innovative tools, and student prior knowledge and experience. In the United Kingdom, the national curriculum is 
designed to help teachers create a classroom environment that facilitates students' problem-solving activities, communication, and the use of mathematical reasoning (United Kingdom Qualifications and Curriculum Authority, 1999). Similarly, the South Korean national mathematics curriculum asks teachers to design classroom environments that facilitate students' active mathematical investigation through interaction with their classmates (Ministry of Education, 2015).

In a mathematics classroom where conceptual understanding is emphasized, students are expected to engage vigorously in learning activities. They are encouraged to compare different representations and ideas, connect related mathematical concepts, and apply acquired knowledge to other tasks (Munter et al., 2015). In this environment, the role of a teacher is that of a facilitator, providing appropriate, challenging tasks to help students engage in learning and use their prior knowledge to acquire new understanding (NCTM, 2014). Thus, student-centered instruction emphasizes individual investigation and student discussion and collaboration (Heyd-Metzuyanim \& Shabtay, 2019). Furthermore, researchers have developed criteria to gauge whether or not teachers are practicing student-centered instruction. To better understand the characteristics of teachers' instructional practices, Carpenter and Lehrer (1999) proposed tasks, tools, and mathematics classroom norms, and NCTM (2014) proposed classroom tasks and discourse and defined the roles of teachers and students.

\section{Sense of Self-Efficacy}

Bandura's (1997) social cognition theory is regarded as one of the conceptual strands of the study of teachers' self-efficacy beliefs (Morali, 2019; Zee \& Koomen, 2016). According to Bandura (1997), the concept of self-efficacy pertains to an individual's belief in their own ability to implement a set of actions and achieve a set of goals. The actions include regulating physical behavior and cognitive and affective states (Bandura, 1997). Hence, teachers' sense of self-efficacy can be assessed to estimate whether or not they initiate and persist in innovative practices despite a challenging environment (Donnell \& Gettinger, 2015; Smith, 1996). In student-centered instruction, teachers share their authority with students, and students are expected to engage with mathematics learning communities as coinvestigators. These innovative classrooms can intimidate teachers accustomed to teacher-centered practices (Lewis, 2014; Smith, 1996). Smith (1996) showed that teachers with a high sense of self-efficacy tended to apply innovative methods, but that teachers with a low sense of self-efficacy were more likely to criticize their students' abilities and motivation and continue teacher-centered practices.

Four factors influence the development of teachers' sense of self-efficacy (Bandura, 1997): mastery experiences (previous successful and failed activities), vicarious experiences (watching others teach and learning from PD), verbal persuasion (feedback from colleagues), and emotional arousal (feelings about the teaching environment). Mastery experiences have the most powerful effect on teachers' sense of self-efficacy (Bandura, 1997; Zee \& Koomen, 2016). However, other factors influence teachers' progress toward mastery and add to the development of self-efficacy (Althauser, 2015; Zee \& Koomen, 2016). Bandura (1997) pointed out that while vicarious experiences 
have a weaker initial effect than mastery experiences, sometimes they can ultimately have a more significant impact than direct experiences. Because people tend to estimate their abilities based on peer success and failure and past learning experiences from college and PD, teachers may sustain a certain level of self-efficacy regardless of the outcome of their own direct experience.

\section{Classroom Stress}

Kyriacou (2001) defined teacher stress as the experience by a teacher of negative emotions resulting from their work as a teacher. Many factors can stress teachers, including classroom behavior management, lack of motivation, curriculum overload, high-stakes tests, inadequate resources, lack of parent support, extra workload, administrator pressure, and new knowledge introduction (Galton \& MacBeath, 2008; Ismail et al., 2019; Klassen \& Chiu, 2010; Kyriacou, 2001).

Furthermore, teacher stress leads to mental and physical illness, inadequate teaching quality, and strained relationships with students (Galton \& MacBeath, 2008; Wilson, 2002; Yoon, 2002). Teachers with high levels of stress tend to spend less time preparing lessons and disengage from teaching, which results in low levels of self-efficacy (Klassen \& Chiu, 2010; Skaalvik \& Skaalvik, 2016; Wilson, 2002). For example, Skaalvik and Skaalvik (2016) found that teachers' perception of student misbehavior influenced their classroom stress and emotional exhaustion, thus lowering the level of teacher self-efficacy. In addition, teachers with high levels of stress are apt to continue with teacher-centered practices (Lewis, 2014; Skaalvik \& Skaalvik, 2017; Wilson, 2002). Teachers stressed by the task of engaging disruptive students might spend more time managing classroom behavior and less time implementing discussion and investigation. Lewis (2014) confirmed that mathematics teachers suffering from class stress tend to avoid implementing student-centered practices. Furthermore, they may feel that their students do not have the ability or motivation to learn mathematics using student-centered practices (Skaalvik \& Skaalvik, 2017).

\section{Professional Development and Instructional Practices}

Researchers have been very interested in PD (Alamri et al., 2018) and have reported positive associations between PD and student-centered instruction (Garet et al., 2001; Lewis, 2014; Roschelle et al., 2010). PD helps teachers not only to gain new instructional methods and curricula but also to learn how to apply these methods in the classroom. For example, after analyzing 1,027 mathematics and science teachers, Garet et al. (2001) reported that PD activities aligned teachers' instructional practices with student-centered instruction. Similarly, Heck et al. (2019) examined 205 North American (US and Canada) mathematics schoolteachers and found that they shifted their approaches to student-centered practices based on the knowledge they acquired from PD. Moreover, Roschelle et al. (2010) examined 220 randomly selected secondary mathematics teachers in Texas and reported similar findings.

In addition, researchers have found that the effects of PD on instruction vary according to contextual factors (Desimone, 2009; Jacob et al., 2017; Santagata et al., 2010). Jacob et al. (2017) examined 105 mathematics teachers in a district serving low-performing students and found that although PD experiences enhanced teachers' mathematical 
knowledge for teaching, the influence of PD on instruction was not significant. Moreover, Santagata et al. (2010) conducted similar studies with 64 mathematics teachers working in low-performing schools and reported that PD could not affect teacher knowledge and practices. The authors explained that unsupportive contextual factors, such as the lack of support from administrators, ineffective PD content, and the emphasis on short-term performance on standardized-tests, nullified the influence of PD on instruction. However, little research has been conducted to examine the influences of teachers' psychological factors on the relationship between PD and instruction.

\section{Professional Development, Classroom Stress, and Self-Efficacy Beliefs}

Studies have showed that teachers' sense of self-efficacy is positively developed after engaging in PD (Althauser, 2015; Carney et al., 2016; Zee \& Koomen, 2016). After examining 4,000 mathematics teachers participating in PD programs, Carney et al. (2016) found that PD programs helped teachers improve their self-efficacy beliefs. Teachers in the study learned new knowledge, observed others succeed in implementing student-centered practices, and received feedback regarding their instructional practices. These experiences enhanced their self-efficacy beliefs.

The literature on the relationship between PD and classroom stress has showed that PD experiences generally bring about a change in teachers' classroom stress (Lewis, 2014; Sandilos et al., 2018). PD helps teachers learn classroom management skills and instructional strategies that can help them effectively manage their teaching demands. However, researchers have found that PD cannot reduce stress caused by organizational factors, such as high-stakes tests and overloaded curricula (Galton \& MacBeath, 2008; Ouellette et al., 2018; Wilson, 2002). Hence, while individual teachers may change their self-efficacy beliefs and instructional practices due to the learning acquired during PD, they may still suffer stress because of external factors they cannot change.

\section{Mathematics Teachers in South Korea}

On the one hand, mathematics teachers in South Korea work under guidelines issued by the Ministry of Education (MOE) and must obtain teacher certification by attending government-approved colleges. Moreover, although it is not mandatory for private schools, public schools can hire only teachers who have passed the National Mathematics Teacher Candidates' Test developed by the MOE. Mathematics teachers are strongly encouraged to use government-approved textbooks as their primary teaching resource and to follow specific plans for school days and hours prescribed by law (MOE, 2015; Mullis et al., 2016).

On the other hand, mathematics teachers have autonomy in the classroom. Although the MOE suggests teaching practices, following them is not compulsory. Teachers can select teaching methods, and school administrators will respect their choices. Thus, even when using the same textbooks, some teachers might focus on drills and practices, and others might be concerned with student investigation (Ko et al., 2015; MOE, 2015). Mathematics teachers can also decide which PD programs they attend and how many per year. Therefore, even though current PD in mathematics teaching in South Korea focuses on introducing innovative teaching practices and curricula (Ko et al., 2015), the teacher has the option not to attend any of these programs. Indeed, according to the 
TIMSS 2015 data, almost 10\% of South Korean teachers of eighth-grade mathematics had not received any PD in mathematics for two years (Mullis et al., 2016).

\section{What We Know and Do Not Know}

To summarize, we know that mathematics teachers' PD experiences influence their selfefficacy beliefs (Althauser, 2015; Carney et al., 2016), classroom stress (Lewis, 2014), and student-centered instruction (Garet et al., 2001; Roschelle et al., 2010). We also know that mathematics instruction is influenced by self-efficacy beliefs (Donnell \& Gettinger, 2015; Smith, 1996) and classroom stress (Lewis, 2014). Additionally, we know the mediating effects of contextual factors on the relationship between PD and instruction. However, as mentioned earlier, we know little about how mathematics teachers' psychological factors, including self-efficacy beliefs and classroom stress, mediate the effects of PD on instruction.

\section{This Study}

In this study, we explore the mediating effects of self-efficacy beliefs and classroom stress on the relationship between PD and student-centered practices. Based on the literature review, we expected that PD experiences would be positively related to selfefficacy and student-centered practices and negatively related to classroom stress. We expected a positive relationship between self-efficacy and student-centered instruction, a negative relationship between classroom stress and self-efficacy, and a negative relationship between classroom stress and student-centered instruction. Specifically, we examined the mediating effects of self-efficacy and classroom stress while modeling a process in which PD influences classroom stress, and, in turn, self-efficacy, concluding with student-centered instruction as the final outcome. Figure 1 shows the theoretical model of this study.

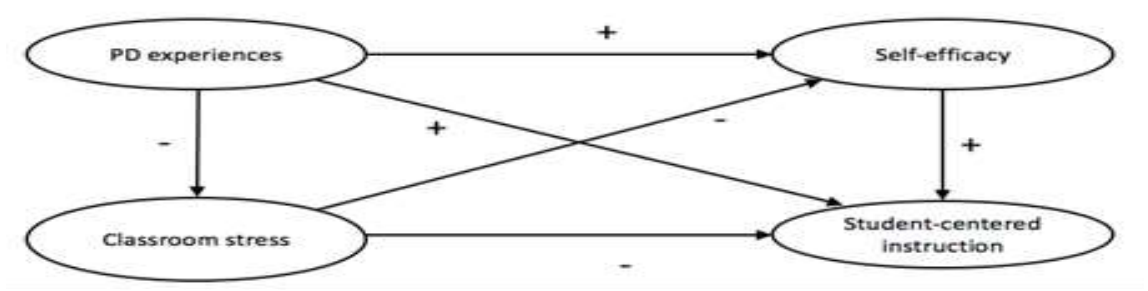

Figure 1

A Hypothesized Model of Relations Between the Study Variables

\section{METHOD}

\section{Data}

We adopted the descriptive quantitative analysis method to examine the relations between the study variables. We used a secondary raw data set collected for the TIMSS 2015 (Mullis et al., 2016). TIMSS researchers randomly selected Korean middle school mathematics teachers from a nationally representative sample using multistage random sampling methods (Martin et al., 2016). To use all available information, the researchers did not delete data with missing variables but handled it with a default setting of Mplus 8 (Muthén \& Muthén, 2017). The sample consisted of 317 teachers of eighth-grade 
mathematics $($ male $=96$, female $=221$ ) selected from 150 schools in Korea .

\section{Measurement}

Teachers were asked to report on their PD experience, classroom stress, self-efficacy, and student-centered instruction. Teachers reported on the following seven PD types relating to their mathematics PD experience within the past two years: content (PD1), pedagogy and instruction (PD2), curriculum (PD3), technology integration (PD4), critical thinking and problem-solving skills (PD5), assessment (PD6), and the ability to address student needs (PD7). Teachers responded using "Yes" (2) or "No" (1) binaryscale options. The variables were reverse-coded. Hence, high scores indicated teachers' active participation in PD. The Cronbach's alpha value, the most widely used reliability index to measure the internal consistency of a scale, was .780. The values ranged from 0 to 1 ; the higher the alpha values, the higher the reliability of a scale. If the alpha values rose above .7, we could safely assume that all items in the scale measured the same concept and that the scale was reliable (Cho \& Kim, 2015).

Teachers reported on their classroom stress levels using the following eight statements: "There are too many students in the classes" (CS1), "I have too much material to cover in class" (CS2), "I have too many teaching hours" (CS3), "I need more time to prepare for class" (CS4), "I need more time to assist individual students" (CS5), "I feel too much pressure from parents" (CS6), "I have difficulty keeping up with all of the changes to the curriculum" (CS7), and "I have too many administrative tasks" (CS8). Response options were on a 4-point scale ranging from "Strongly Agree" (1) to "Strongly Disagree" (4). The variables were reverse-coded; high scores indicated a high level of classroom stress among teachers. The Cronbach's alpha value was .815 .

Teachers reported on their self-efficacy in implementing the following nine classroom objectives: inspiring students to learn mathematics (SE1), showing students problemsolving strategies (SE2), providing challenging tasks for the highest-achieving students (SE3), adapting teaching to engage students' interests (SE4), helping students appreciate the value of learning mathematics (SE5), assessing student comprehension of mathematics (SE6), improving the understanding of struggling students (SE7), making mathematics relevant to students (SE8), and developing students' higher-order thinking skills (SE9). Response options were on a 4-point scale ranging from "Very high" (1) to "Low" (4). The variables were reverse-coded; high scores indicated a high level of selfefficacy. The Cronbach's alpha value was .896.

Teachers reported on how often they implemented the following student-centeredinstruction objectives: relate the lesson to students' daily lives (SC1), ask students to explain their answers (SC2), ask students to complete challenging exercises (SC3), encourage classroom discussions (SC4), link new content to student prior knowledge (SC5), ask students to decide their own problem-solving procedures (SC6), and encourage students to express their ideas (SC7). Response options were on a 4-point scale ranging from "Every or almost every lesson" (4) to "Never" (1). The variables were reverse-coded; high scores indicated the teacher had a higher commitment to student-centered instruction. The Cronbach's alpha value was .821 . 


\section{Data Analysis}

We first conducted exploratory factor analysis (EFA) to examine the independence of factors and confirmatory factor analysis (CFA) to estimate the measurement model fit. Because the total sample size was relatively small, we did not split the data into an initial and a validation sample. Rather, we conducted a two-factor analysis using the same sample. Then, we estimated bivariate correlations between latent variables. Next, we conducted structural equation modeling (SEM) to examine the theoretical model. We used the weighted least square mean and variance to estimate our data, which were robust for analyzing categorical variables (Muthén \& Muthén, 2017). To test the model fit, we used $\chi^{2}$ statistics. However, because $\chi^{2}$ statistics are sensitive to sample size, we used other fit indices as follows: the comparative fit index (CFI), the root mean square error of approximation (RMSEA), and the standardized root mean square residual (SRMR). Following $\mathrm{Hu}$ and Bentler (1999), we evaluated model fit between the hypothesized model and the observed data using these guidelines: (a) RMSEA and SRMR value of less than .05 indicated a good fit, and .08 indicated an acceptable fit; and (b) CFI value of greater than .95 indicated a good fit, and .90 indicated an acceptable fit. Figure 2 shows data analysis procedures for this study.

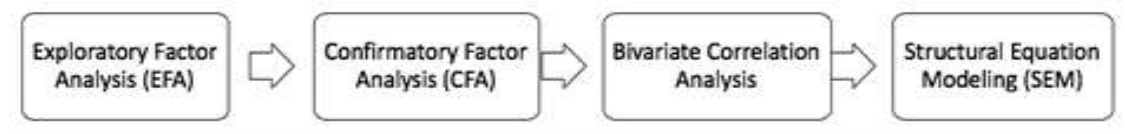

Figure 2

Data Analysis Procedures

\section{FINDINGS}

\section{Preliminary Factor Analysis}

We conducted EFA with four factors to confirm the hypothesized factor structure. All items showed high factor loadings, and the EFA model had good model fit $\left(\chi^{2}[465, N=\right.$ $317]=6830.781, p<.05$, RMSEA $=.049$, CFI $=.959$, and SRMR $=.049)$. Next, we conducted CFA. The results indicated that the proposed model had an acceptable fit to the data $\left(\chi^{2}[465, N=317]=6830.781, p<.001\right.$, RMSEA $=.040$, CFI $=.966$, and SRMR $=.062)$, and all factor loadings were significant at $p<.05$.

Table 1

Rotated Factor Analysis for All Items

\begin{tabular}{llllllll}
\hline \multicolumn{2}{l}{ Factor 1 $(\mathrm{PD})$} & \multicolumn{2}{l}{ Factor 2 $(\mathrm{CS})$} & \multicolumn{2}{l}{ Factor 3 (SE) } & \multicolumn{2}{l}{ Factor 4 (SC) } \\
\hline Item & Loadings & Item & Loadings & Item & Loadings & Item & Loadings \\
\hline PD1 & $0.851^{*}$ & CS1 & $0.634^{*}$ & SE1 & $0.815^{*}$ & SC1 & $0.440^{*}$ \\
PD2 & $0.841^{*}$ & CS2 & $0.725^{*}$ & SE2 & $0.749^{*}$ & SC2 & $0.753^{*}$ \\
PD3 & $0.755^{*}$ & CS3 & $0.787^{*}$ & SE3 & $0.637^{*}$ & SC3 & $0.563^{*}$ \\
PD4 & $0.561^{*}$ & CS4 & $0.773^{*}$ & SE4 & $0.767^{*}$ & SC4 & $0.554^{*}$ \\
PD5 & $0.664^{*}$ & CS5 & $0.664^{*}$ & SE5 & $0.780^{*}$ & SC5 & $0.674^{*}$ \\
PD6 & $0.694^{*}$ & CS6 & $0.546^{*}$ & SE6 & $0.749^{*}$ & SC6 & $0.705^{*}$ \\
PD7 & $0.637^{*}$ & CS7 & $0.524^{*}$ & SE7 & $0.691^{*}$ & SC7 & $0.725^{*}$ \\
& & CS8 & $0.658^{*}$ & SE8 & $0.716^{*}$ & & \\
& & & SE9 & $0.797^{*}$ & & \\
\hline
\end{tabular}


Note. $\mathrm{PD}=$ professional development, $\mathrm{CS}=$ classroom stress, $\mathrm{SE}=$ self-efficacy, $\mathrm{SC}=$ student-centered instruction. $* p<.05$ (two-tailed tests).

Table 1 shows factor loadings for all items. The loading scores represent the strength of the correlations between factors and items; higher scores indicate a higher correlation. Generally, scores ranged from -1 to 1 .

\section{Bivariate Correlation Analysis}

Table 2 shows Pearson's bivariate correlations $(r)$, means $(\mathrm{M})$, and standard deviation (SD) of four factors. The Pearson's $r$ value is positive if high values of one variable tend to associate with high values of another variable. Moreover, higher $r$ values indicate higher associations between two variables (Hayes, 2017). The table shows that PD was weakly but positively correlated with self-efficacy $(r=.214, p<.01)$ and studentcentered instruction $(r=.258, p<.01)$. In addition, self-efficacy was moderately and positively associated with student-centered instruction $(r=.692, p<.01)$. However, classroom stress was not significantly correlated with PD, self-efficacy, and studentcentered instruction. These results support the notion that teachers' PD experiences may contribute to the development of higher self-efficacy and raise student-centered instruction. In addition, classroom stress may not influence self-efficacy and studentcentered instruction.

Table 2

Pearson's Correlations and Descriptive Statistics

\begin{tabular}{lllll}
\hline & 1 & 2 & 3 & 4 \\
\hline 1) PD & - & & & \\
2) Classroom stress & 0.016 & - & & \\
3) Self-efficacy & $.214^{* *}$ & 0.023 & - & - \\
4) Student-centered instruction & $.258^{* *}$ & -0.079 & $.692 * *$ & - \\
$\mathrm{M}(\mathrm{SD})$ & $1.427(.485)$ & $2.828(.710)$ & $3.020(.711)$ & $2.790(.801)$ \\
\hline Note. ${ }^{* *} p<.01$ (two-tailed tests) & & &
\end{tabular}

\section{Structural Equation Modeling}

We conducted SEM to test the theoretical model. SEM helps researchers examine direct and indirect paths of study of variable relationships in a model. The model had an acceptable fit with the data $\left(\chi^{2}[465, N=317]=6830.781, p<.001\right.$, RMSEA $=.040$, $\mathrm{CFI}=.966$, and SRMR $=.062)$. All parameter estimates in the model were statistically significant at the 0.01 levels. Tables 3 and 4 and Figure 3 show the results of the structural model. The unstandardized regression coefficient (B) indicates the change in the outcome associated with a one-unit change in the predictor. The standardized regression coefficient $(\beta)$ indicates the change in the outcome associated with a onestandard-deviation change in the predictor (Hayes, 2017). For example, the significant coefficient value .669 ( $\mathrm{SE} \rightarrow \mathrm{SC}, \beta=.669)$ implies a unit change in self-efficacy (SE); there is a .669 standard-deviation change in the student-centered practices (SC), holding other variables constant at their mean.

Regarding direct effects, the effect of PD on student-centered instruction was significantly positive when other variables were constant in the model $(\mathrm{PD} \rightarrow \mathrm{SC}, \beta=$ 
$.116, p<.05)$. Furthermore, there were significantly positive relations between PD and self-efficacy ( $\mathrm{PD} \rightarrow \mathrm{SE}, \beta=.214, p<.01)$ and between self-efficacy and studentcentered instruction ( $\mathrm{SE} \rightarrow \mathrm{SC}, \beta=.669, p<.01)$. Meanwhile, classroom stress showed a negative association with student-centered instruction ( $\mathrm{CS} \rightarrow \mathrm{SC}, \beta=-.096, p<.05)$. Regarding indirect (mediating) effects, our study found that increased PD was positively associated with increased student-centered instruction through self-efficacy (PD $\rightarrow \mathrm{SE}$ $\rightarrow \mathrm{SC}, \beta=.143, p<.01)$. The other two indirect paths were not statistically significant $(\mathrm{PD} \rightarrow \mathrm{CS} \rightarrow \mathrm{SC}$ and $\mathrm{PD} \rightarrow \mathrm{CS} \rightarrow \mathrm{SE} \rightarrow \mathrm{SC}$ ). However, the total indirect effect, the sum of three indirect effects, was statistically significant $(\beta=.142, p<.01)$. These seemingly paradoxical outcomes are possible because the total indirect effect is a sum of all indirect effects (Hayes, 2017). Regarding total effect, PD showed a positive association with student-centered instruction $(\beta=.258, p<.01)$.

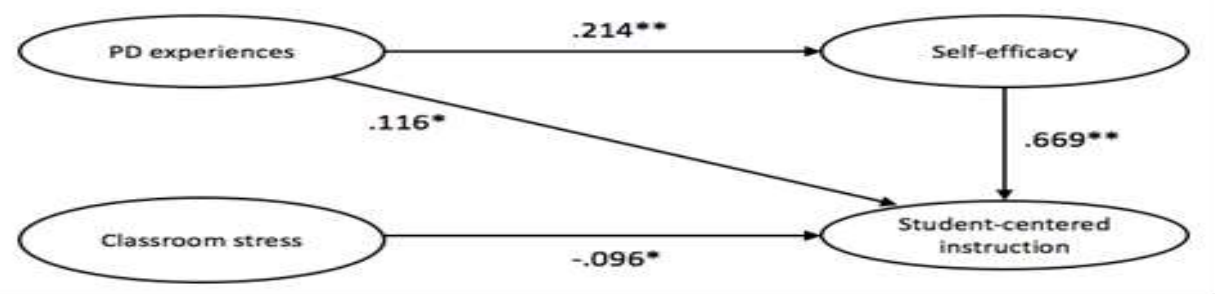

Figure 3

Structural Equation Model Showing Standardized Path Coefficients

Note. The lines and arrows indicate direct and significant effects of predictor on outcome.

Table 3

Unstandardized and Standardized Coefficients

\begin{tabular}{|c|c|c|c|c|c|c|c|c|c|}
\hline Factor & Item & B & $\beta$ & SE of B & Factor & Item & B & $\beta$ & SE of B \\
\hline \multirow{7}{*}{ PD } & PD1 & 1 fixed $* *$ & $0.799 * *$ & - & \multirow{9}{*}{ SE } & SE1 & 1 fixed** & $0.743 * *$ & - \\
\hline & PD2 & $1.047 * *$ & $0.836^{* *}$ & 0.077 & & SE2 & $1.041^{* *}$ & $0.774 * *$ & 0.049 \\
\hline & PD3 & $0.939 * *$ & $0.750 * *$ & 0.071 & & SE3 & $1.059 * *$ & $0.787^{* * *}$ & 0.054 \\
\hline & PD4 & $0.766^{* *}$ & $0.612 * *$ & 0.084 & & SE4 & $1.024 * *$ & $0.761^{* *}$ & 0.049 \\
\hline & PD5 & $0.937 * *$ & $0.748 * *$ & 0.076 & & SE5 & $1.079 * *$ & $0.802^{* * *}$ & 0.052 \\
\hline & PD6 & 0.89 ** & $0.711 * *$ & 0.072 & & SE6 & $1.024 * *$ & $0.761^{* * *}$ & 0.056 \\
\hline & PD7 & $0.867 * *$ & $0.692 * *$ & 0.073 & & SE7 & $1.014 * *$ & $0.754 * *$ & 0.052 \\
\hline \multirow{9}{*}{ CS } & $\mathrm{CS} 1$ & 1fixed** & $0.641 * *$ & - & & SE8 & $1.039 * *$ & $0.773^{* * *}$ & 0.051 \\
\hline & CS2 & $1.141^{* *}$ & $0.732 * *$ & 0.074 & & $\begin{array}{l}\text { SE9 } \\
\end{array}$ & $1.099 * *$ & $0.817^{* * *}$ & 0.051 \\
\hline & $\mathrm{CS} 3$ & $1.237 * *$ & $0.793 * *$ & 0.088 & \multirow{7}{*}{ SC } & $\underline{\mathrm{SC} 1}$ & 1fixed** & $0.583^{* * *}$ & - \\
\hline & CS4 & $1.154 * *$ & $0.740 * *$ & 0.077 & & $\mathrm{SC} 2$ & $1.225 * *$ & $0.715^{* * *}$ & 0.113 \\
\hline & CS5 & $1.025^{* * *}$ & $0.657 * *$ & 0.084 & & SC3 & $1.152 * *$ & $0.672^{* * *}$ & 0.120 \\
\hline & CS6 & $0.878^{* * *}$ & $0.563 * *$ & 0.08 & & SC4 & $1.096^{* * *}$ & $0.639^{* * *}$ & 0.121 \\
\hline & CS7 & $0.845^{* * *}$ & $0.542 * *$ & 0.08 & & SC5 & $1.110 * *$ & 0.648 ** & 0.113 \\
\hline & CS8 & $1.021^{* * *}$ & $0.655^{* * *}$ & 0.076 & & SC6 & $1.402 * *$ & $0.818^{* * *}$ & 0.119 \\
\hline & & & & & & SC7 & $1.358^{* * *}$ & $0.792^{* * *}$ & 0.117 \\
\hline
\end{tabular}


Note: $\mathrm{B}, \beta$, and SE refer to unstandardized coefficients, standardized coefficients, and standard error of unstandardized coefficients, respectively. $* * p<.01$ (two-tailed tests).

Table 4

Direct, Indirect, and Total Effects between Latent Variables

\begin{tabular}{rlllclll}
\hline Direct effects & $\mathrm{B}$ & $\beta$ & $\mathrm{SE}$ & Indirect (mediating) effects & $\mathrm{B}$ & $\beta$ & $\mathrm{SE}$ \\
\hline $\mathrm{PD} \rightarrow \mathrm{CS}$ & .013 & .016 & .061 & $\mathrm{PD} \rightarrow \mathrm{CS} \rightarrow \mathrm{SC}$ & -.001 & -.002 & .005 \\
\hline $\mathrm{PD} \rightarrow \mathrm{SE}$ & $.199^{* *}$ & $.214^{* *}$ & .061 & $\mathrm{PD} \rightarrow \mathrm{SE} \rightarrow \mathrm{SC}$ & $.104^{* *}$ & $.143^{* *}$ & .033 \\
\hline $\mathrm{PD} \rightarrow \mathrm{SC}$ & $.085^{*}$ & $.116^{*}$ & .039 & $\mathrm{PD} \rightarrow \mathrm{CS} \rightarrow \mathrm{SE} \rightarrow \mathrm{SC}$ & .001 & .001 & .001 \\
\hline $\mathrm{CS} \rightarrow \mathrm{SE}$ & .023 & .020 & .069 & Total indirect effect & $.103^{* *}$ & $.142^{* *}$ & .034 \\
\hline $\mathrm{CS} \rightarrow \mathrm{SC}$ & $-.087^{*}$ & $-.096^{*}$ & .044 & Total effects & & & \\
\hline $\mathrm{SE} \rightarrow \mathrm{SC}$ & $.525^{* *}$ & $.669^{* *}$ & .054 & $\mathrm{PD} \rightarrow \mathrm{SC}$ & $.188^{* *}$ & $.258^{* *}$ & .054 \\
\hline
\end{tabular}

Note. ${ }^{*} p<.05$ (two-tailed tests). ${ }^{* *} p<.01$ (two-tailed tests). Total effects indicate the sum of direct and indirect effects.

\section{DISCUSSION}

Previous studies have focused on contextual factors to explain the different effects of PD on instruction, but teachers' psychological factors have received little attention. In this study, we examined the mediating effects of mathematics teachers' self-efficacy beliefs and classroom stress on the relationship between their PD and student-centered instruction.

Teachers' self-efficacy beliefs are important factors influencing PD experiences and instruction. Building upon previous self-efficacy research, this study found that there are significant mediating effects of self-efficacy beliefs on the relationship between PD and instruction. The results align with the findings of Donnell and Gettinger (2015) and Thoonen et al. (2011), that is, teachers' self-efficacy beliefs were the most critical factors in explaining teachers' learning and teaching practices. Studies have showed that PD experiences positively enhance teachers' understanding of innovative instructional materials and methods, which may increase their confidence in using these practices and in turn lead them to implement student-centered practices in the classroom (Garet et al., 2001; Smith, 1996; Zee \& Koomen, 2016). These findings are also consonant with Desimone's (2009) argument that PD influences teachers' psychological factors and effectively changes their practices in classrooms. Conversely, aligned with Smith's (1996) study, teachers with a low sense of self-efficacy are less likely to be open to innovative practices and minimize their efforts to acquire new knowledge during PD. Consequently, these teachers are likely to continue teacher-centered teaching methods despite learning from PD.

Our study also found that teachers who participated in PD tended to implement studentcentered instruction; PD has a significant direct effect on student-centered instruction, holding other variables constant at their mean. This result is consistent with the findings of Heck et al. (2019), Garet et al. (2001), and Roschelle et al. (2010). These authors found significant improvement in mathematics teachers' student-centered instruction after participating in PD; learning from PD may increase teachers' willingness to 
implement new innovative practices in their classroom. However, these findings were contrary to the results of Jacob et al. (2017) and Santagata et al. (2010), who did not find a significant effect of PD on mathematics teachers' instruction. The contradictory findings may be the result of different contextual factors. In the studies by Jacob et al. (2017) and Santagata et al. (2010), the participants were teachers working in disadvantaged districts serving low-performing students, and school administrators emphasized student performances on standardized tests. Consequently, teachers were more concerned about improving student performance on tests than increasing mathematical understanding, which made these teachers implement drill-and-rote learning. However, in this study, participants were selected from a nationally representative sample, which means that the influences of certain school contexts were nullified, allowing us to analyze the general effects of PD on instruction.

Moreover, similar to other studies, we found a significant direct effect of classroom stress on student-centered instruction (Lewis, 2014; Skaalvik \& Skaalvik, 2017; Yoon, 2002). Skaalvik and Skaalvik (2017) explained that classroom stress caused teachers to implement teacher-centered practices and minimize student-centered practices (e.g., discussion and investigation) to control disruptive students. However, contrary to our hypothesis and other studies (Lewis, 2014; Sandilos et al., 2018), the mediating effects of classroom stress on the relationship between PD and instruction were not significant. Lewis (2014) and Sandilos et al. (2018) reported that PD reduced teacher stress, which in turn positively influenced their student-centered instructions. We, however, did not find such effects. One possible explanation for this unexpected finding pertains to the characteristics of classroom stress. When teachers are stressed because of organizational factors they cannot control (e.g., high-stakes testing), they still suffer from stress regardless of PD (Galton \& MacBeath, 2008; Ouellette et al., 2018; Wilson, 2002).

\section{CONCLUSION}

The findings of this study support the idea that mathematics teachers' self-efficacy beliefs are critical factors mediating the relationship between PD and student-centered instruction. Moreover, we determined that there is a direct and positive relationship between PD and student-centered instruction and PD and self-efficacy beliefs. However, while we could find the direct and negative effect of classroom stress on their studentcentered instruction, the mediating effect of classroom stress on the relationship between PD and instruction was not significant. In sum, teachers with more PD experiences and a high level of self-efficacy are more likely to implement student-centered instruction.

\section{RECOMMENDATION}

Considering the positive mediating effects of self-efficacy on the relationship between PD and student-centered instruction, school administrators should help teachers increase their confidence in teaching mathematics. The administrators might provide additional materials or recruit expert teachers who could support other teachers as they implement student-centered instruction. Moreover, school administrators and policy makers should ensure that all mathematics teachers can participate in PD without any distractions. The endeavors to increase teachers' confidence in their mathematics teaching ability and 
participation in PD could eventually enhance their commitment to student-centered instruction. Moreover, researchers studying the effects of PD on instruction should consider the mediating effects of teacher self-efficacy beliefs. If studies do not take selfefficacy into account, they might yield misleading results. For further study, we recommend analyzing other psychological factors that may influence the relationship between PD and instruction, such as teacher motivation and professional orientation. Furthermore, given the nonsignificant mediating effects of classroom stress in this study, further research is needed to elucidate the effects of classroom stress on the relationship between PD and instruction with more comprehensive items, such as questions about organizational factors.

\section{LIMITATIONS}

This study had several critical limitations. First, we used a secondary data set, so only the existing indicators in the TIMSS 2015 data set were available to explore the structural relations of variables. Although all latent variables were unidimensional constructs, other researchers have reported more complex constructs of individual variables. For example, we analyzed teachers' self-efficacy as a unidimensional construct. However, our colleagues have reported that self-efficacy is a multidimensional construct that includes confidence in classroom management, student engagement, and instructional practices (Zee \& Koomen, 2016). Second, we used teachers' self-reported data. Thus, it may be difficult to ensure the reliability of our findings. Although all data were collected anonymously by TIMSS researchers, teachers may have deliberately overrated themselves to present themselves as higher-quality teachers. Future researchers should examine whether teachers' self-reported data aligns with their actual practices by using student ratings or researcher observations. Third, the scoring of some items was not consistent. For example, items measuring self-efficacy were given on a 4-point scale, very high, high, medium, and low; we used the same scale that the TIMSS researchers (2015) used in their study. Our findings might have been different had we used a more consistent scale, such as a 5-point scale, very high, high, medium, low, and very low. Furthermore, future studies could be conducted with more thorough instruments to confirm the relationships examined in this study.

\section{REFERENCES}

Alamri, N. M., Aldahmash, A. H., \& Alsharif, K. M. (2018). Emerging trends in research on math teacher professional development. International Journal of Instruction, 11(3), 91-106. https://doi.org/10.12973/iji.2018.1137a.

Althauser, K. (2015). Job-embedded professional development: Its impact on teacher self-efficacy and student performance. Teacher Development, 19(2), 210-225. https://doi.org/10.1080/13664530.2015.1011346.

Bandura, A. (1997). Self-efficacy: The exercise of control. W. H. Freeman and Company. 
Carney, M. B., Brendefur, J. L., Thiede, K., Hughes, G., \& Sutton, J. (2016). Statewide mathematics professional development: Teacher knowledge, self-efficacy, and beliefs. Educational Policy, 30(4), 539-572. https://doi.org/10.1177/0895904814550075.

Carpenter, T., \& Lehrer, R. (1999). Teaching and learning mathematics with understanding. In E. Fennema, \& T. Romberg (Eds.), Mathematics classrooms that promote understanding (pp. 19-32). Lawrence Erlbaum.

Cho, E., \& Kim, S. (2015). Cronbach's coefficient alpha: Well known but poorly understood. Organizational Research Methods, 18(2), 207-230. https://doi.org/10.1177/1094428114555994.

Desimone, L. M. (2009). Improving impact studies of teachers' professional development: Toward better conceptualizations and measures. Educational Researcher, 38(3), 181-199. https://doi.org/10.3102/0013189x08331140.

Donnell, L. A., \& Gettinger, M. (2015). Elementary school teachers' acceptability of school reform: Contribution of belief congruence, self-efficacy, and professional development. Teaching and Teacher Education, 51, 47-57. https://doi.org/10.1016/j.tate.2015.06.003.

Galton, M., \& MacBeath, J. (2008). Teachers under pressure. Sage.

Garet, M. S., Porter, A. C., Desimone, L., Birman, B. F., \& Yoon, K. S. (2001). What makes professional development effective? Results from a national sample of teachers. American Educational Research Journal, 38(4), 915-945. https://doi.org/10.3102/00028312038004915.

Hayes, A. F. (2017). Introduction to mediation, moderation, and conditional process analysis: A regression-based approach. The Guilford Press.

Heck, D. J., Plumley, C. L., Stylianou, D. A., Smith, A. A., \& Moffett, G. (2019). Scaling up innovative learning in mathematics: Exploring the effect of different professional development approaches on teacher knowledge, beliefs, and instructional practice. Educational Studies in Mathematics, 102(3), 319-342. https://doi.org/10.1007/s10649-019-09895-6.

Heyd-Metzuyanim, E., \& Shabtay, G. (2019). Narratives of 'good' instruction: Teachers' identities as drawing on exploration vs. acquisition pedagogical discourses. ZDM Mathematics Education. 51, 41-554. https://doi.org/10.1007/s11858-018-01019-3

Hu, L., \& Bentler, P. M. (1999). Cutoff criteria for fit indexes in covariance structure analysis: Conventional criteria versus new alternatives. Structural Equation Modeling: A Multidisciplinary Journal, 6(1), 1-55. https://doi.org/10.1080/10705519909540118.

Ismail, S. N., Abdullah, A. S., \& Abdullah, A. G. K. (2019). The effect of school leaders' authentic leadership on teachers' job stress in the eastern part of peninsular Malaysia. Int J of Instruction, 12(2), 67-80. https://doi.org/10.29333/iji.2019.1225a.

Jacob, R., Hill, H., \& Corey, D. (2017). The impact of a professional development program on teachers' mathematical knowledge for teaching, instruction, and student 
achievement. Journal of Research on Educational Effectiveness, 10(2), 379-407. https://doi.org/10.1080/19345747.2016.1273411.

Klassen, R. M., \& Chiu, M. M. (2010). Effects on teachers' self-efficacy and job satisfaction: Teacher gender, years of experience, and job stress. Journal of Educational Psychology, 102, 741-756. https://doi.org/10.1037/a0019237.

Ko, J. H., Kim, T. E., \& No, W. K. (2015). An analysis of the actual status about the connection of teaching and learning mathematics between elementary school and junior high school. J of Korea Society Edu Stu in Math: School Mathematics, 17(1), 135-156.

Kyriacou, C. (2001). Teacher stress: Directions for future research. Educational Review, 53(1), 27-35. https://doi.org/10.1080/00131910124115.

Lewis, G. M. (2014). Implementing a reform-oriented pedagogy: Challenges for novice secondary mathematics teachers. Mathematics Education Research Journal, 26(2), 399419. https://doi.org/10.1007/s13394-013-0092-5.

Martin, M. O., Mullis, I. V. S., \& Hooper, M. (2016). Methods and procedures in TIMSS 2015. Retrieved from TIMSS \& PIRLS International Study Center, Lynch School of Education, Boston College, and International Association for the Evaluation of Educational Achievement (IEA) website: http://timssandpirls.bc.edu/publications/timss/2015-methods.html.

Ministry of Education (2015). Mathematics curricula.

Morali, G. (2019). Examination of the reading self-efficacy of learners of Turkish as a foreign language regarding some variables. International Journal of Instruction, 12(1), 1445-1458. https://doi.org/10.29333/iji.2019.12192a.

Mullis, I. V. S., Martin, M. O., Foy, P., \& Hooper, M. (2016). TIMSS 2015 international results in mathematics. Retrieved from Boston College, TIMSS \& PIRLS International Study Center website: http://timssandpirls.bc.edu/timss2015/internationalresults/.

Munter, C., Stein, M. K., \& Smith, M. A. (2015). Dialogic and direct instruction: Two distinct models of mathematics instruction and the debate(s) surrounding them. Teachers College Record, 117(11), 1-32.

Muthén, L. K., \& Muthén, B. O. (2017). Mplus user's guide. Los Angeles, CA: Muthén \& Muthén.

National Council of Teachers of Mathematics. (2014). Principles to action: Ensuring mathematical success for all.

Ouellette, R. R., Frazier, S. L., Shernoff, E. S., Cappella, E., Mehta, T. G., MaríñezLora, A., \& Atkins, M. S. (2018). Teacher job stress and satisfaction in urban schools: Disentangling individual-, classroom-, and organizational-level influences. Behavior therapy, 49(4), 494-508. https://doi.org/10.1016/j.beth.2017.11.011.

Roschelle, J., Shechtman, N., Tatar, D., Hegedus, S., Hopkins, B., Empson, S., ... Gallagher, L. P. (2010). Integration of technology, curriculum, and professional 
development for advancing middle school mathematics: Three large-scale studies. American Educational Research Journal, 47(4), 833-878. https://doi.org/10.3102/0002831210367426.

Sandilos, L. E., Goble, P., Rimm-Kaufman, S. E., \& Pianta, R. C. (2018). Does professional development reduce the influence of teacher stress on teacher-child interactions in pre-kindergarten classrooms? Early Childhood Research Quarterly, 42, 280-290. https://doi.org/10.1016/j.ecresq.2017.10.009.

Santagata, R., Kersting, N., Givvin, K. B., \& Stigler, J. W. (2010). Problem implementation as a lever for change: An experimental study of the effects of a professional development program on students' mathematics learning. $J$ of Research on Educational Effectiveness, 4(1), 1-24. https://doi.org/10.1080/19345747.2010.498562.

Skaalvik, E. M., \& Skaalvik, S. (2016). Teacher stress and teacher self-efficacy as predictors of engagement, emotional exhaustion, and motivation to leave the teaching profession. Creative Edu, 7(13), 1785-1799. https://doi.org/10.4236/ce.2016.713182.

Skaalvik, E. M., \& Skaalvik, S. (2017) Teacher stress and teacher self-efficacy: relations and consequences. In T. McIntyre, S. McIntyre, \& D. Francis (Eds.), Aligning perspectives on health, safety, and well-being book series: Educator stress. (pp. 101126). Springer.

Smith, J. P. (1996). Efficacy and teaching mathematics by telling: A challenge for reform. Journal for Research in Mathematics Education, 27(4), 387-402. https://doi.org/10.2307/749874.

Thoonen, E. E. J., Sleegers, P. J. C., Oort, F. J., Peetsma, T. T. P., \& Geijsel, F. P. (2011). How to improve teaching practices: The role of teacher motivation, organizational factors, and leadership practices. Educational Administration Quarterly, 47(3), 496-536. https://doi.org/10.1177/0013161x11400185.

United Kingdom Qualifications and Curriculum Authority. (1999). The national curriculum: Handbook for primary teachers in England. Department for Education and Employment \& Qualifications and Curriculum Authority.

Wilson, V. (2002). Feeling the strain: An overview of the literature on teachers' stress. The Scottish Council for Research in Education.

Yoon, J. S. (2002). Teacher characteristics as predictors of teacher-student relationships: Stress, negative affect, and self-efficacy. Social Behavior and Personality: An Int Journal, 30(5), 485-493. https://doi.org/10.2224/sbp.2002.30.5.485.

Zee, M., \& Koomen, H. M. (2016). Teacher self-efficacy and its effects on classroom processes, student academic adjustment, and teacher well-being: A synthesis of 40 years of research. $R$ of Edu Res, 86(4), 981-1015. https://doi.org/10.3102/0034654315626801 